\title{
LOS LIBROS DE CORO DE SANTA MARÍA Y SAN PEDRO DE ARCOS DE LA FRONTERA.
}

\author{
Rosario Marchena Hidalgo \\ UNIVERSIDAD DE SEVILLA
}

\section{RESUMEN}

Dos documentos de 1609 certifican la confección de los libros de coro de Santa María y San Pedro por parte del escribano Nicolás Tazón. En la actualidad de los libros conservados, 19 en la primera parroquia y 3 en la segunda, solo uno lleva la fecha citada pero otros, pese al cúmulo de calamidades por las que han pasado, presentan características que permiten situar a muchos de ellos en el siglo XVII.

Palabras clave: Libros de coro; Iglesias de Santa María y San Pedro; Arcos de la Frontera; Cádiz; Siglo XVII; Pergaminos; Miniaturas y miniaturistas; policromía; uso y conservación.

\section{ABSTRACT}

Two documents dated on 1609 attribute true authorship to scribe Nicolás Tazón of two parish churchs' Choir Books, both of them, Santa María and San Pedro, located in Arcos de la Frontera. At present time, from all conserved books, 19 in the first church and 3 in the second one, only one of them is dated on the mentioned year, however much others should be dated in the 17th century in spite of all the calamities they have happened through.

Key words: Choir's books; Santa María and San Pedros's Churches; Arcos de la Frontera; Cádiz; 17th century; parchments; miniatures and miniaturists; policromía, use and conservation.

Dos documentos del Archivo Histórico Provincial de Sevilla, de 7 de mayo de 1609, recogen la fabricación, por parte del escribano de letra de obra Nicolás Tazón, de los libros de coro de las parroquias de Santa María y San Pedro de Arcos. Nicolás Tazón, vecino de Sevilla en la collación de San Vicente, debe gozar ya por estos años de un gran prestigio como lo demuestra el que se le haya hecho un encargo tan sustancioso y que esté avalado por un escultor de la talla de Andrés Docampo. Trabaja también para la Catedral de Sevilla aunque su nombre no aparece 
recogido en los documentos nada más que en la tercera nómina de mayo y en la tercera y cuarta de junio de $1614^{1}$. Forma parte de un grupo numeroso de escribanos raspadores, solfadores, iluminadores y encuadernadores, Jerónimo Bravo, Giuseppe Carrera, Morata, Villaviciosa y Andrés Camacho, todos a las órdenes de Melchor Riquelme, que van a abordar la ingente tarea de transformar los libros de coro para adaptarlos al Nuevo Rezado Romano vigente en la Archidiócesis Hispalense desde el día de San Silvestre, el 31 de diciembre, de 1574. Se trataba de desencuadernar los libros ya existentes que se ajustaban al rito hispalense, raspar o borrar los folios para aprovecharlos, volverlos a escribir, introducir otros nuevos, puntar, iluminar y encuadernarlos de nuevo. El año de 1614 debió de ser de gran actividad pues en él coinciden en el taller catedralicio la mayor cantidad de artesanos relacionados con la fabricación del libro de todo el siglo XVII. Esto lo ratifica una desaparecida inscripción del folio de guarda delantero del libro de coro 38 en la que se decía, entre otras cosas, que el deán y cabildo encomendaron al bachiller Sebastián Vicente Villegas que corrigiera los libros de canto llano de la catedral por lo que se compusieron 140 libros entre septiembre de 1613 y julio de $1615^{2}$. Esta acumulación de trabajo es la que hace que, en contra de lo que había ocurrido con anterioridad y de lo que sería norma en los años siguientes, se les pague a estos artesanos un jornal diario ajustado a sus aptitudes y no una cantidad determinada al terminar la obra. Nicolás Tazón cobra siete reales por jornada de trabajo, más que el resto de los colaboradores de este taller, más incluso que Jerónimo Bravo al que siempre se le llama oficial de Melchor Riquelme el maestro de la librería de la Santa Iglesia.

La oleada de corrección de los libros de canto llano no se redujo únicamente a los de la Catedral de Sevilla, ni a estos años sino que el ejemplo fue seguido por todas las parroquias y conventos de la archidiócesis más pronto o más tarde. La labor de composición de los libros que recogían el abandonado rito hispalense fue enorme pues había que alterar el orden existente, introducir partes nuevas y eliminar otras pero siempre respetando las iluminaciones antiguas. Esto se hizo porque era una forma de abaratar costes, para cuyo fin también se emplearon gran cantidad de folios raídos y repescados, pero también por la conciencia que había del valor de estas miniaturas y de la dificultad que entrañaba el igualarlas en calidad. Unas veces son los documentos los que recogen el arreglo de los libros de coro como aquel del Archivo Histórico Provincial de Sevilla, de 1626, en el que Diego Sánchez Aguayo cobra por haber aderezado los libros de San Miguel de Sevilla ${ }^{3}$. Otras veces la huella de esa corrección ha quedado plasmada en los mismos corales como ocurre en dos, el 10 y el 27, de San Juan de Marchena, en los que da su imprescindible visto bueno Sebastián Vicente Villegas, ya para este año de 1631, maestro de ceremonias de la catedral.

A la vez que se corregían los libros existentes se elaboraban otros nuevos. En el año 1609, en que Nicolás Tazón está haciendo los de las parroquias de Santa María y San Pedro de Arcos, Simón Rodríguez Carvallo, vecino de Sevilla en la collación de Omnium Sanctorum, está haciendo otro para San Juan de Marchena ${ }^{4}$. También en el mismo año Melchor Riquelme, vecino de Sevilla en la collación de San Vicente, está escribiendo unos corales para

Archivo Catedral de Sevilla, Sección IV, libro 311, folios 25 vuelto, 29 y 29 vuelto.

BOUTELOU SOLDEVILLA y FERNÁNDEZ CASANOVA: "Libros de coro de la Catedral de Sevilla”. Boletín de la Real Academia de San Fernando. Madrid, 1884, pág. 179.

3 Archivo de Protocolos Notarial de Sevilla. Oficio 4 de Alonso de Escobedo, libro $1^{\circ}$ de 1626. Archivo Histórico Provincial de Sevilla. Protocolo 2533, folio 913 recto.

4 RAMOS SUÁREZ, Manuel A.: "Libros para orar, cantar y ver. Aproximación al estudio de los libros de coro de la iglesia de San Juan de Marchena”. Actas de las II Jornadas sobre historia de Marchena (Historia de Marchena. Volumen II). Marchena bajo los Ponce de León: formación y consolidación del señorío (Siglos XIII- XVI). Madrid, 1996, pág. 259. 
dicha iglesia de Sevilla ${ }^{5}$ y al siguiente continúa con su tarea de escribirlos e iluminarlos ${ }^{6}$. En 1623 Andrés Camacho, vecino de Sevilla en la collación de San Andrés, hace unos libros de coro para San Martín de Sevilla y al siguiente uno para la iglesia de Villanueva del Río ${ }^{8}$ y dos más para la de Santa María de Manzanilla ${ }^{9}$. Estos datos dejan de manifiesto que son escribanos vecinos de Sevilla los que están llevando a cabo la tarea de remodelación o nueva elaboración de los libros corales de la archidiócesis en este primer tercio del siglo XVII por lo que el parecido de estos, en materiales, encuadernación, contenido, iluminación, costes, estado de conservación..., con los de la Catedral de Sevilla es grande no difiriendo más que en el menor tamaño de aquellos.

Los libros de coro de Santa María y San Pedro de Arcos son de pergamino, tienen makulatur $\mathrm{y}$ folio de guarda delantero y trasero y sus cubiertas de tablas forradas de piel de becerro llevan clavería y cierres (bullones y manezuelas). Están foliados parcialmente en números romanos rojos ${ }^{10}$, en romanos negros ${ }^{11} \mathrm{y}$ en árabes negros ${ }^{12}$ habiendo varios sin foliar de los que la mayoría son de la parroquia de San Pedro. Los folios tienen unos amplios márgenes proporcionales tanto al tamaño de ellos como al del espacio escrito. En líneas generales la altura de la parte escrita es igual a la anchura total del folio. La distribución de la escritura es a base de conjuntos formados por el pentagrama con notas cuadradas que reflejan el canto llano y el texto bajo él. El número de conjuntos por folio varía de cuatro a seis ${ }^{13}$. La tinta empleada para el texto escrito y las notas musicales es negra reservándose la roja para los pentagramas, los títulos y poco más (Fot.1). Estos corales responden a la actuación más frecuente en el siglo XVII que consistió en no iluminar con historias y orlas sino únicamente con letras cardinales. Las letras capitales, que enfatizan el inicio de una parte de lo recogido en el libro, pueden ser miniadas, es decir aquellas que se realizan con una amplia gama de brilantes colores, verdes, rojos, azules, amarillos, morados, muy matizados usando básicamente motivos vegetales en los que las hojas se vuelven dejando ver su envez ( Fot. 2). Su colorido y el agitado movimiento de los elementos que las forman suplen el esplendor del oro bruñido que en el siglo XVII ya se aplica a las letras miniadas de una manera más restringida. Mucho más abundantes, y a veces más grandes, son las letras de compás para iluminadores $^{14}$ mal llamadas mudéjares. Su altura es igual a su anchura que a veces incluso es mayor con lo que su proporción se ajusta al 1:1 propia de este tipo de letras. En ellas se emplean dos colores, el azul del cobalto y el rojo del cinabrio, que en las más ricas, que también son las más grandes, se combinan para formar el cuerpo de la letra originando un tipo de ellas

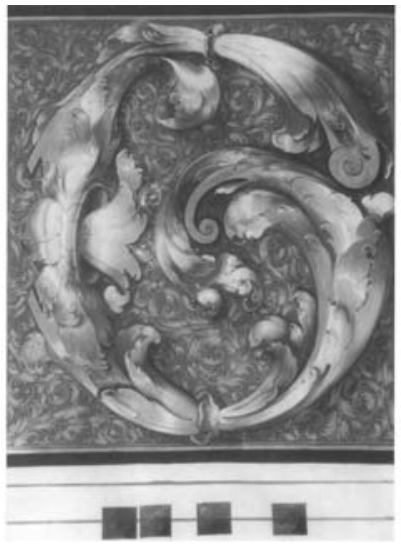

\footnotetext{
A.P.N.S. Oficio 4 de Pedro del Carpio, libro $3^{\circ}$ de 1609. A.H.P.S. Protocolo 2449, folios 909 recto- 910 recto. A.P.N.S. Oficio 4 de Pedro del Carpio, libro $5^{\circ}$ de 1610. A.H.P.S. Protocolo 2455 , folio 1025 vuelto.

A.P.N.S. Oficio 4 de Alonso de Escobedo, libro $1^{\circ}$ de 1623. A.H.P.S. Protocolo 2514, folios 999 recto y vuelto. A.P.N.S. Oficio 4 de Alonso de Escobedo, libro $1^{\circ}$ de 1624. A.H.P.S. Protocolo 2520, folio 301 vuelto. A.P.N.S. Oficio 4 de Alonso de Escobedo, libro $4^{\circ}$ de 1624. A.H.P.S. Protocolo 2523, folios 487 recto-488 vuelto. Libros 1, 7, 818 y 9 de Santa María y otro sin número de San Pedro.

Libros 2, 3, 6, 15, 16 y 17 de Santa María.

Libros 5, 11, 12, 13 y 14 de Santa María.

Cuatro: libro 10 de Santa María. Cinco: libros 2, 5, 9 y 11 de Santa María. Seis: libro 7 de Santa María y uno sin número de San Pedro.

14 YCÍAR, Juan de: Arte Subtilísima intitulada ortografía pratica por la cual se enseña a escribir perfectamente. Zaragoza, 1548. Bartolomé de Nájera. Folios G IV vuelto- G VII.
} 


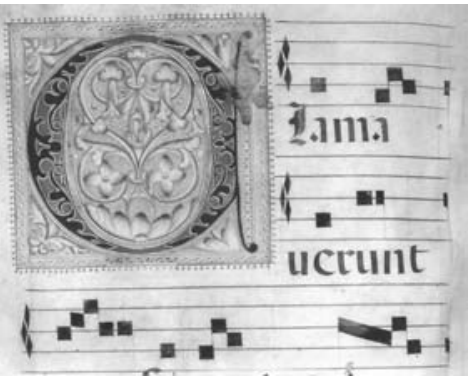

que se conocen como a tinta partida (Fot. 3). En el fondo sobre el que van las letras también aparecen los dos colores repartidos en tres franjas azul-roja-azul o viceversa. Las más sencillas, que suelen ser más pequeñas y de las que a veces hay varias por folio, tienen el cuerpo íntegramente rojo o azul yendo sobre un fono azul o rojo. Pese a la parquedad cromática, las distintas intensidades de las tintas rojas y azules, el que el blanco del pergamino intervenga en las gradaciones de color y la precisión y minuciosidad de los escribanos les resta monotonía a este tipo de iluminación. Las otras mayúsculas empleadas en estos libros de coro son las letras quebradas ${ }^{15}$ realizadas en tinta negra, la misma del texto del que forman parte, trazadas con gran habilidad, un grado de complicación variable y a veces adornadas con dibujos ligeros en su interior (Fot. 6).

El 7 de mayo de 1609, Nicolás Tazón otorga carta de pago en Sevilla de 300 reales a cuenta de los libros de coro que está haciendo para la parroquia de Santa María. Los ha recibido de manos del escultor Andrés de Ocampo, que por estos años está trabajando en el retablo mayor y en el de la capilla del Bautismo ${ }^{16}$, en representación de Pedro de Mendoza, clérigo presbítero, mayordomo de la fábrica de la iglesia, presentando como testigos de su conocimiento al clérigo, vecino de Sevilla en la collación de La Magdalena, Juan de Solórzano y a su hermano Giusepe Tazón ${ }^{17}$. Todos los personajes que aparecen en el documento, excepción hecha del mayordomo de Santa María, son vecinos de Sevilla, incluso el que da la orden de pago don Diego Fernández de Córdoba, deán y canónigo de la Catedral de Sevilla. La intensa relación con esta ciudad se aprecia en los arquitectos que están al cargo de las obras de la parroquia en distintos momentos, maestros mayores de la archidiócesis en muchos casos, Alonso Rodríguez, Diego de Riaño, Martín de Gainza, Hernán Ruiz

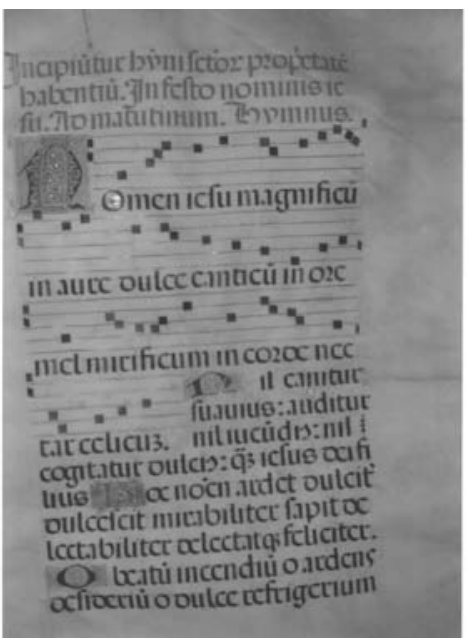

II, o de la Real Fábrica de Tabacos, Vicente Bengoechea, y en los escultores, además de Andrés Docampo, Jerónimo Hernández y Juan Bautista Vázquez el Mozo que trabajan aquí18.

Guiados por este documento nos dirigimos a Santa María donde se guardan los 19 libros existentes en la iglesia en una alacena situada en el costado del coro, en la misma posición que ocupaba en la colegial de El Salvador de Sevilla antes de ser derribada para construir el edificio actual. Su estado de conservación no es bueno habiendo hecho estragos en ellos la polilla especialmente. Llevan casi todos en el makulatur o el folio de guarda delanteros un recuadro de papel pegado que dice: Este libro se compuso por disposición del Sacristán mayor primer Sochantre de esta Parroquia D. José Almendra Infante e expensas de él mismo. Año 1877. Solo uno de los libros, el 11, cambia un poco el sentido de la nota diciendo que el arreglo se hizo a expensas del feligrés don Mariano José Cabrera. La

IBIDEM, folios H VI vuelto y H VII.

FALCÓN MÁRQUEZ, Teodoro: Iglesias de Santa María y San Pedro. Arcos de la Frontera. Sevilla, 1995, págs. 8 y 10.

A.P.N.S. Oficio 4 de Pedro del Carpio, libro $2^{\circ}$ de 1609. A.H.P.S. Protocolo 2448, folios 346 recto y vuelto

FALCÓN MÁRQUEZ: Op. Cit., págs. 4, 6 y 8. 
mayoría de estos corales corresponden al siglo XVII y por su encuadernación y por contenido son muy parecidos a los de la Catedral de Sevilla, denotando en algunos casos la misma mano.

El libro 4 es de tamaño semejante a los de otras iglesias de la archidiócesis ${ }^{19}$, tiene 110 folios, su estado de conservación es malo pues, entre otras cosas, los makulatur y folios de guarda están apolillados. Una serie de inscripciones, de distintos momentos, aparecen al principio: en el makulatur delantero Contiene las vísperas y antífonas, en el folio de guarda delantero que fue arreglado en 1877, en el folio 1 Dominica prima Adventus y debajo, en letra cursiva, La hizo Manuel Gamaza. La fecha de ejecución que de este libro es el año 1609 según reza sobre una letra E(cce) de compás a tinta partida de buen tamaño ${ }^{20}$, del folio 1 vuelto. Esta mayúscula tiene todas las características de este tipo de letras incluída la fecha que porta, algo que es frecuente en los libros de coro del siglo XVII. Este es uno de los libros o, mejor dicho, los restos de él de los que realizara Nicolás Tazón en 1609. De ningún otro coral tenemos la seguridad de que fuera de los hechos por este escribano pero algunos tienen características que enlazan con las de este momento en general y con las del libro 4 en particular.

El libro 1, algo menor de tamaño ${ }^{21}$ que el anteriormente citado, tiene 160 folios y su estado de conservación es malo pues está sucio, comido de polilla, tiene los folios de guarda y makulatur hechos de remiendos y el color corrido por la humedad. Tras el consabido cartel del arreglo en 1877 en el folio de guarda delantero y el título, Psalterium diurnum, que aparece en el folio 1, hay tres letras en el folio 1 vuelto con el color muy perdido, características ajenas a las del siglo XVII y diversos tamaños ${ }^{22}$. En el folio 99 vuelto, al que le falta la esquina superior, una $\mathrm{C}$ (onditor) ${ }^{23}$ miniada enlaza perfectamente por sus características con las de este tipo del siglo XVII de los corales de la Catedral de Sevilla.

El libro 7, algo mayor ${ }^{24}$, tiene 136 folios, no tiene folios de guarda y su clavería está muy deteriorada. En el makulatur delantero dice Vísperas y antífonas y en el folio 1 Dominica Resurrectionis Domini. Todo el libro está lleno de pequeñas letras de compás alternando las rojas sobre fondo azul con las azules sobre fondo rojo.

El libro 8, más grande que todos los demás de esta iglesia ${ }^{25}$, tiene actualmente 98 folios, está muy deteriorado, no conserva la piel que forraba la madera de la tapa ni la clavería, no tiene makulatur ni folios de guarda y no termina aunque en un intento de remediar su penosa situación se le ha echado una primorosa costura en el folio 20. Directamente sobre la madera de la tapa aparece Índice libro 8 de Vísperas y en el folio 1 In festo Sancti Iacobi Apostoli. En el interior del libro hay dos magníficas letras, una A(ccesit) en el folio 1 vuelto y otra A(ssumpsit) en el 19 vuelto, de compás, a tinta partida, del mismo tamañ $0^{26}$ que cumplen rigurosamente con la proporción de este tipo de letras y que son las mayores de todos los libros de coro de las dos parroquias de Arcos. En el folio 95 vuelto una espléndida $\mathrm{B}$ (eatus) ${ }^{27}$ responde al mismo tipo de las anteriormente citadas.

El libro 18, menor que el anterior ${ }^{28}$, ha sufrido los efectos de la guillotina, tiene la clavería incompleta aunque conserva los folios de guarda y makulatur. En el delantero dice Hora de Prima. Hora de Tertia. Hora de Sexta. Hora de Nona y en el folio 1 lo del arreglo de 1877. El título está borrado. Lo correspondiente al siglo XVII llega unicamente hasta el folio 92 hasta donde hay foliación en números romanos rojos. Lo que sigue es añadido posteriormente, de ínfima calidad que se

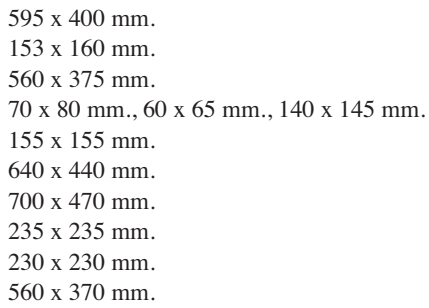


aprecia, sobre todo, en la calavera que decora el Oficio de Difuntos. Pero en los folios anteriores aparecen dos letras de compás a tinta partida, la $\mathrm{I}(\mathrm{am})^{29}$ del folio 1 vuelto y la $\mathrm{D}(\mathrm{ilexi})^{30}$ del 57 vuelto, que tienen todas las características propias de principios del siglo XVII como por ejemplo cubrir el fondo del recuadro en el que se encajan con unos minúsculos arquillos constantemente repetidos en los libros de coro de la catedral.

Cualquiera de estos cuatro libros analizados, $1,7,8$ y 18, podrían haber sido hechos por Nicolás Tazón como lo fue el 4 , según muestran la letra miniada y las de compás que se ven en ellos. Pero en la iglesia de Santa María hay otros muchos libros que están fechados en los años 30 del siglo XVII y que participan de algunas de las características ya analizadas.

El libro $9^{31}$, que conserva la clavería, los makulatur y los folios de guarda aunque clavados a las tapas, está foliado en números romanos rojos lo mismo que el 1, 7, 8 y 18 lo que nos puede inducir a pensar que son todos de las mismas fechas. El año de ejecución aparece inequívocamente en 3 folios. En el folio 1 vuelto una inscripción dice Este libro se hico siendo Mayordomo el Licenciado Cristóbal Pascual año 1634, en el folio 131 sobre una H(odie) aparece la fecha 1634 y en el folio 145 sobre una P(ascha) Año 1634. Si todos los libros de Santa María tienen relación con los de la Catedral de Sevilla éste ha sido hecho por la misma mano lo que se deduce del número de conjuntos de pentrama y texto por folio, 5 , de los elementos de las letras capitales y de las letras quebradas sobre las que se ve la I vista en ellos ${ }^{32}$ que, con toda probabilidad responde a la inicial de un escribano al servicio de la Santa Iglesia, Jerónimo Bravo. En este libro 9 aparecen una serie de inscripciones: en el makulatur delantero Maitines Diversas. Dominica Resurr..., en el folio 1 In Nativitate Domini. Ad matutinum Invitatorium, en el folio 101 Dominica Resurrectionis Domini y en el 126 In solemnitatis sacratissimi corporis Christi. Iniciando cada una de esas 3 partes hay letras capitales de gran tamaño: la C(hristus) miniada del folio 1 vuelto $^{33}$, la S(urrexit) del folio 101 vuelto $^{34}$; la C(hristi) del folio 126 vuelto. Las de compás a tinta partida, que son las dos últimas, van sobre un rectángulo cubierto por los inconfundibles dibujos de ese momento y rodeado por una estreha cenefa de trenza.

El libro $2^{35}$, de 182 folios, conserva la clavería bastante completa, parecida a la de los libros de la catedral, y los folios de guarda y makulatur. En el delantero lleva el índice (Misas) ...propias de los meses IX, X, XI, XII y las comunes. Pese a que de nuevo aparezca en el folio de guarda delantero la composición de 1877, una inscripción del folio 1 vuelto nos da la fecha: Mayordomo Cristóbal García Pascual 1635. Ratifica su adscripción a esa primera mitad del siglo XVII la letra miniada $\mathrm{H}$ (erodes) del folio 1 vuelto $^{36}$.

El libro 6, Pentecostem (sic), de buen tamaño ${ }^{37}$, es un ejemplo de libro mal conservado al que le faltan muchos clavos, no empieza ni termina, no tiene folios de guarda, los dos makulatur son aprovechados y está remendado. En el makulatur delantero aparece el índice Oficio de Consepción (sic). Los 35 primeros folios son producto de una composición posterior al siglo XVII en donde se han ido situando letras capitales ${ }^{38}$ abominables que compiten en tamaño $^{39} \mathrm{y}$ en pretensión. Pero a partir del folio 36, Propium a missarum de tempore. In die Pentecostes, se

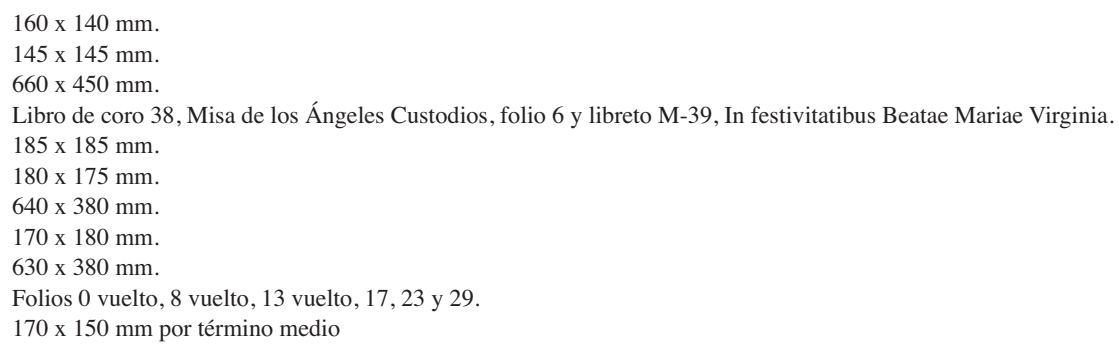


inicia el antiguo libro que en el que era el folio 1 vuelto lleva una $S$ (piritus) miniada ${ }^{40}$ del tipo que estamos estudiando. En el folio 53 vuelto hay una C(ibavit) ${ }^{41}$ de compás a tinta partida de la misma calidad que las vistas en libros anteriores. La inscripción del folio 1 vuelto nos aclara la fecha de esta parte del coral: Este libro hiço siendo Mayordomo el Licenciado Cristóbal García Pascual. Año de 1635. El libro termina tan mal como empezó: con el folio 126 clavado en la tapa de madera a manera de makulatur.

El libro 14, que no tiene folios de guarda, conserva completa la clavería en la que de nuevo apreciamos un gran parecido con la de los libros de la Catedral de Sevilla, tiene 126 folios y lleva, como es lo habitual en los libros de esta iglesia, el índice Dominica Resurrección en el makulatur delantero. Tras el folio 1 Propium missarum de tempore, en el 1 vuelto, hay una gran $\mathrm{R}$ miniada ${ }^{42}$ en parte borrada por la humedad, calamidad frecuente de la que tampoco se han librado estos libros.

El libro $3^{43}$, que tiene 222 folios, tampoco está muy bien conservado pues tiene los folios de guarda y makulatur apolillados y al folio 1 le falta el quinto superior. El makulatur delantero nos dice Contiene las Vísperas propias de los meses del 30 del IX al 31 del VII, el folio de guarda delantero recoge de nuevo el arreglo de 1877 y en el folio 1 aparece Propium Sanctorum. In die XXX Novembris. In festo S. Andres Apostoli. La inscripción del folio 1 vuelto nos aclara la fecha de ejecución: Este libro se hiço siendo Mayordomo el Licenciado Alonso Fernández Mancheño. Año de 1633. En el mismo folio hay una S(alve) miniada ${ }^{44}$.

El libro $11^{45}$ conserva la clavería completa del tipo semejante a la de los libros de la catedral, no tiene folios de guarda y completa la nómina de desperfectos que puede sufrir un libro al tener los folios primeros y últimos quemados. Es difícil saber cuál es el número de folios que tiene puesto que la numeración empieza por más de 200 y termina en el 150 que, por cierto, va detrás del 151. Por lo demás responde a las características de casi todos los libros de Santa María: en el makulatur delantero lleva el índice y la tan repetida cartela impresa que en este caso acusa una variante, Este libro se compuso por disposición del Sacristán Mayor Primer Sochantre de esta Parroquia José Almendra Infante a expensas del feligrés Don Mariano José Cabrera, año de 1877. El folio 1 vuelto, que justamente está en la mitad del libro, dice Anno Domini 1639 Maiordomo El Licenciado Alonso Fernández Mancheño. En el folio 1, donde empezaba el libro original, aparece el título Propium missarum de Sanctis y la letra N(unc) ${ }^{46}$ del folio 1 vuelto es una miniada muy rica, propia de este momento.

El libro 12, prácticamente igual al anterior en el tamaño ${ }^{47}$, está encuadernado, como todos, en tabla forrada de piel de becerro, con clavería, no tiene folios de guarda pero si makulatur. En el desorden de la numeración (empieza en el 157 hasta el 246 y luego viene el 1 para terminar con el 62) también se parece al anterior. En el makulatur delantero lleva la cartela impresa del arreglo de 1877 y en el folio 1, es decir, pasada la mitad del libro, aparece el título, Propium missarum de Sanctis. En la Vigilia de San Andrés Apóstol. En el folio 1 vuelto una D(ominus) miniada $^{48}$ acoge en el ductus la inscripción que lo fecha: Este libro se hiço siendo mayordomo el Licenciado Alonso Ferndández. Mancheño. Año 1639.

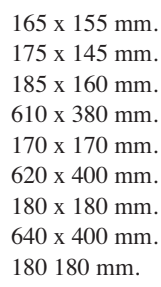


Así pues 12 de los libros de la iglesia de Santa María son, total o parcialmente, del siglo XVII y sus características tan parecidas a los de la catedral que necesariamente, conocido el prestigio de que gozaban los escribanos y miniaturistas de Sevilla, los autores deben ser los mismos.

Dos de los otros siete libros de esta iglesia son muy parecidos entre sí, por la encuadernación, el contenido, el tipo de letra, porque han sufrido el mismo tipo de avatares, porque están incompletos, guillotinados y con los colores corridos por la humedad. Son los número 15 y 16, los más antiguos de todos, del siglo XV y están llenos de letras de compás góticas con salidas, algunas de pequeño tamaño. El $15^{49}$ conserva la clavería completa, semejante a algunos corales de la catedral, no tiene folios de guarda aunque si makulator delantero y trasero. Ni empieza ni acaba y ha sufrido el efecto de la guillotina en los márgenes superiores de los folios por lo que ha perdido la numeración original. En el makulator delantero dice: Índice. Misas de dominicas. Todo el libro está lleno de preciosas letras de compás góticas, rojas sobre fondo azul o viceversa, en general de pequeño tamaño ${ }^{50}$. Muy especial es la de compás a tinta partida del folio $51^{51}$ con una gran salida que abarca íntegramente el margen interior del folio y parte del superior e inferior. Casi iguales son las de los folios 58 vuelto y 62 vuelto.

El libro $16^{52}$, con la clavería igual que el anterior, no tiene folios de guarda aunque sí makulator delantero y trasero. Está foliado en números romanos rojos al principio pero luego, al haber desaparecido estos por la guillotina, se ha seguido en grandes números negros hasta el folio 187 que es el último. Además tiene los colores corridos por la humedad aunque se ha intentado arreglar la mala situación del libro con el pespunte del folio 29. En el folio 1 donde empieza la Dominica primera de Adviento hay una $\mathrm{A}(\mathrm{d})^{53}$ gótica, de compás con salida que ocupa el margen interior. Bastantes letras de compás de las que lleva este libro ${ }^{54}$ tienen también salidas como la $\mathrm{P}(\mathrm{uer})^{55}$ del folio 46 vuelto que corre por el margen exterior e inferior aunque aquí haya sido guillotinada.

El libro $5^{56}$ conserva la clavería completa y está mejor conservado que otros. Hasta el folio 87 la numeración se ha hecho en romanos negros y a partir de aquí y hasta el 95 está sin foliar. En el makulator delantero dice: Índice. Oficio del Señor San Josefy de la Assumpción. En el folio de guarda delantero aparece la inscripción siguiente: Se hizo este libro siendo mayordomo desta iglesia mayor y más antigua de la Assumpción Don Clemente Antonio de Baena y Manzano y Sochantre Don Francisco Lozano. Año de 1767. Pese a ser del siglo XVIII este libro pasó también por la renovación que se les hizo a todos los corales de Santa María en 1877 como atestigua la cartela del folio de guarda delantero vuelto. En el folio 1 empieza el Oficio de San José. Las letras capitales, la I(acob) del folio 1 vuelto, la I(ustus) del 14, la A(ssumpta) del 15 vuelto, todas ellas de buen tamaño ${ }^{57}$, y otras más pequeñas, son de una calidad mediocre.

Los otros 4 libros restantes, 10,13, 17 y uno sin numerar, de tamaños semejantes, son de difícil clasificación pese a que uno de ellos lleve el nombre de Manuel Gamaza, porque a algunos de ellos le faltan pedazos enteros, ni empiezan ni terminan, no tienen título y, en fin, resumen en ellos todo el cúmulo de desventuras que pueden caer sobre un coral. El libro $10^{58}$ que

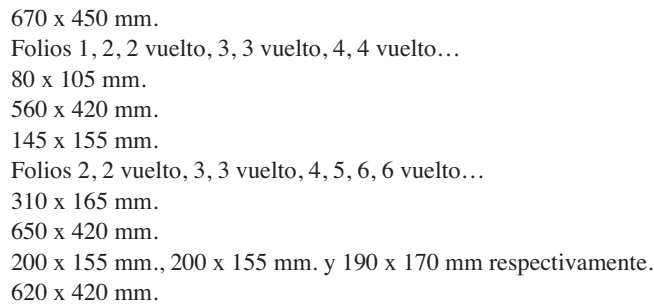


no tiene folios de guarda, que está quemado en el primer y último folio y que está completamente desorganizado, pues empieza en el folio 65 y termina en el 244, como indica la foliación en números romanos negros, está, pese a todo ello, bastante bien conservado. En el makulatur delantero aparece: Índice. De Enero a Mayo y luego la consabida cartela del arreglo de 1877.

El libro $13^{59}$ que tiene la clavería, semejante a la de los libros de coro de la Catedral de Sevilla, incompleta, que no tiene folio de guarda delantero, que no empieza y que tiene dos formas de foliación distintas, hasta el folio 194 en números romanos negros, luego en árabes hasta el 204 y aún tiene tres folios más sin numerar está, pese a todo, bien conservado. En el makulatur delantero lleva el Índice. Común de Misas. Las únicas letras mayúsculas que tiene son las quebradas.

El libro $17^{60}$ tiene la clavería incompleta, el folio de guarda delantero clavado sobre el makultur, estuvo foliado en números romanos rojos de los que quedan huellas aunque ahora lo está en árabes negros hasta el folio 110 habiendo 19 folios más sin numerar, no empieza y tiene el makulatur trasero muy remendado. Lo más inquietante de este coral es que en el folio de guarda delantero aparezca el nombre de Manuel Gamaza, el mismo del libro 4, el único que lleva la fecha de 1609 por donde hemos empezado este estudio. Debajo dice: Libro 17, Kiries, Glorias, Credo, Santus (sic) y Agnus.

El último libro de coro de Santa María no tiene número ${ }^{61}$, tiene las tapas de madera, de pino flandes, al aire, casi no conserva clavería ni folios de guarda, está sin foliar, ni empieza ni termina, está desencuadernado y no tiene iluminación alguna. En el primer folio dice ...dis virgines sequuntur... y en el último...Festum Patrocinii S. Joseph...

Pese a no conservar los libros de esta iglesia ninguna historia, lo que queda muestra un pasado brillante enraizado en la mejor tradición de escritura e iluminación sevillanas. Desgraciadamente no se nos permitió ver las dos magníficas vitelas que en 1933 se encontraban en Santa María y que Domínguez Bordona reprodujera diciendo que si hacía mención de ellas era en la duda de que hubieran pertenecido a los libros litúrgicos ${ }^{62}$. Una de las dos representa los Desposorios místicos de Santa Catalina, en la que el Niño, recostado sobre el regazo de su madre, se dispone a colocar el simbólico anillo en el dedo de Santa Catalina ante la presencia de Santa Inés y Santa Lucía. Todo en la vitela es riquísimo desde el dosel bajo el que se sientan la Virgen y Santa Catalina hasta las ricas vestiduras. Igualmente rico y brillante suponemos que debe ser el color. Está firmada en 1609, el mismo año en el que Nicolás Tazón está haciendo los libros de coro, por Luis Lagarto. Pero hubo dos miniaturistas con ese mismo nombre: Luís Lagarto de la Vega, probablemente sevillano, que marchó a México hacia 1584 y allí, entre otras labores, acometió en 1600 la de iluminar los libros de coro de la Catedral de Puebla, y su hijo Luís de la Vega Lagarto que parece haber colaborado junto a sus hermanos en esta magna tarea de su padre terminada en $1611^{63}$. De ninguno de los dos miniaturistas hay constancia de que estuviera España en 1609 por lo que si la fecha se ratifica la vitela debió ser realizada en México. No fue esta la única obra que había en España de Luis Lagarto pues dice Carderera y recoge el Conde de Viñaza que en 1624 vio en Sevilla dos vitelas de esta fecha y la firma de Luis Lagarto, una de ellas con el tema de la Concepción de la Virgen ${ }^{64}$.

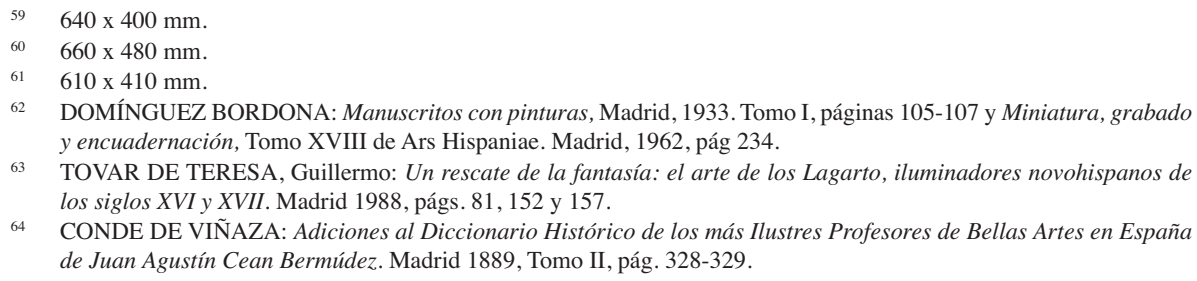

64 CONDE DE VIÑAZA: Adiciones al Diccionario Histórico de los más Ilustres Profesores de Bellas Artes en España de Juan Agustín Cean Bermúdez. Madrid 1889, Tomo II, pág. 328-329. 
La otra vitela, firmada Paulus brame (o bra me) $f$ según Domínguez Bordona, está realizada por Paulus bra como deja claro el resto de la inscripción: $m e$ f(ecit). Representa a Cristo Resucitado sobre la tapa del sepulcro acompañado por dos soldados y dos ángeles. La historia está rodeada por una orla cuyos ángulos y partes centrales están ocupados por ocho clípeos donde se alojan escenas de la vida de Jesús, Pentecostés, San Miguel y otros santos. Sin haberlas visto, sin conocer reproducción alguna en color, poco podemos agregar a la breve descripción que da Domínguez Bordona.

El 7 de mayo de 1609, Nicolás Tazón otorga una carta de pago reconociendo haber recibido de Andrés de Ocampo en nombre de Miguel Farfán, presbítero mayordomo de la iglesia de San Pedro, 100 reales a cuenta de los libros de coro que estaba haciendo para esta parroquia además de otros 50 que había recibido antes. El mandamiento para que se le librara esa cantidad lo dio, lo mismo que en el caso de los libros de coro de Santa María, don Diego Fernández de Córdoba, deán y canónigo de la Santa Iglesia. De nuevo presenta como testigos de conocimiento al clérigo Juan de Solórzano y a su hermano Giusepe Tazón ${ }^{65}$.

En San Pedro quedan actualmente tres libros de coro aunque en origen debieron ser diez a juzgar por los huecos que tiene la alacena destinada a contenerlos. No están numerados aunque en el makulatur trasero de uno de ellos diga este libro es el cuatro, alguno no está foliado, han sufrido guillotina, tienen folios cortados, uno de ellos no tiene título, están apolillados, destrozados, quemados y mojados. Con la dificultad que entraña estudiar libros en esas condiciones lo hemos hecho minuciosamente determinando que uno es del siglo XVII por una fecha que aparece dentro y que otro lo es claramente por el estilo.

El libro Propium missarum de sanctus. In festo sanctorum martirum Marcelini, Petri atque Eu smi. Introitus, de buen tamaño ${ }^{66}$, es muy uniforme, foliado en números romanos rojos hasta el folio 162 tras el cual se incluyen otros siete más, muy toscos, sin numerar. Su estado de conservación no es demasiado malo pese a tener la clavería incompleta, el makulatur delantero destrozado y el trasero aprovechado de otro libro, no tener folios de guarda y haber perdido un poco de color por haberse mojado. En el folio 1 hay una C(lamaverunt) de compás a tinta partida ${ }^{67}$ característica del siglo XVII, en el folio 22 una letra quebrada con una I en la cartela y en el 27 otra con II en la cartela tal como se ve en algunas letras de los libros de la catedral. Este puso ser un libro, a juzgar por el estilo, de los que hiciera Nicolás Tazón en 1609.

Otro libro, In festo sancti Iuliani episcopi et confesori et per octavam. Die XXVIII Ianuarii ${ }^{68}$ que tiene 165 folios, no está numerado, tiene la clavería, de modelo diferente que la del anterior, incompleta, tiene el makulator delantero y el trasero destrozados, no tiene folios de guarda y es todo él un cúmulo de desgracias pues está destrozado, quemado, apolillado, mojado, tiene folios $\operatorname{cortados}^{69}$, está corregido con tachaduras y no termina ${ }^{70}$. En el folio 4 vuelto una S quebrada lleva la inscripción Año Serena 1677. En el folio 19 hay una letra de compás a tinta partida con salida. El libro tiene distintas partes. A partir del segundo cuaderno empiezan a aparecer unas pequeñas letras de compás ${ }^{71}$, rojas o azules sobre fondo a la inversa, a veces con salida como la $\mathrm{S}$ del folio $76^{72}$ propias del siglo XVII. Pero en el resto del libro se ven letras quebradas con toques muy perdidos de amarillo que las sitúan en el siglo XVI. La decoración de este libro es abundante llegando a haber a veces hasta nueve letras por folio.

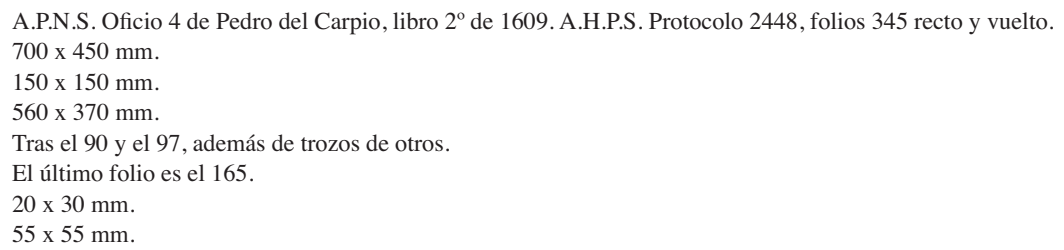


El tercer libro de la iglesia de San Pedro no tiene título pero en el makulatur trasero dice este libro es el cuatro. Más pequeño que los anteriormente $\operatorname{citados}^{73}$, tiene 70 folios y es el que está en peor estado: sin folios de guarda, con los makulatur aprovechados y llenos de remiendos, ni empieza, pues el primer folio es el 113, ni termina, guillotinado al final por haber aprovechado cuadernillos de un libro mayor Las letras capitales son paupérrimas, rojas o azules, están mal trazadas pues, reservadas por el escribano para que las hiciera un iluminador, finalmente las acometió un inexperto. En medio de este panorama negativo el libro conserva la clavería central que es igual a la del libro Propium missarum de sanctus.

La historia de los libros de coro de las parroquias de Santa María y San Pedro es igual a la de otros sitios. En uso durante unos cuantos de cientos de años se han tenido que ir adaptando a las necesidades litúrgicas de cada momento. No siempre estas remodelaciones se han hecho con un criterio de conservación de las iluminaciones anteriores y por buenos escribanos. Pero por delante del desgaste por el uso, de los variados accidentes a los que están expuestos, de los que las quemaduras de las velas y la humedad quizás sean los más frecuentes, y de algún acto vandálico lo que más daño está haciendo a estos libros es el olvido en el que están sumidos.

\section{APÉNDICE DOCUMENTAL}

\section{NICOLÁS TAZÓN. 7-V-1609. LIBRO DE CORO PARA LA IGLESIA DE SANTA MARÍA DE ARCOS.}

A.P.N.S. Oficio 4 de Pedro del Carpio, libro $2^{\circ}$ de 1609

A.H.P.S. Protocolo 2448, folios 346 recto y vuelto.

Sepan cuantos esta carta vieren como yo Nicolás Tazón, escritor de libros, vecino desta ciudad de Sevilla en la collación de San Vicente otorgo e conozco que recibo de Andrés de Ocampo, escultor, vecino desta ciudad en la dicha collación de San Vicente questá presente en nombre de Pedro de Mendoza, clérigo presbítero mayordomo de la fábrica de la iglesia de Santa María de la ciudad de Arcos, 300 reales para en cuenta de los maravedises que montare la obra de los libros de canto que estoy haciendo para la dicha iglesia de Santa María los cuales recibo realmente y con efecto en reales de plata y moneda de bellón en presencia del escribano público y testigos yuso escritos de que yo el presente escribano público doy fe y son en poder de mi el dicho Nicolás Tazón los dichos 300 reales de que doy por pagado a mi voluntad y los recibo en virtud de un mandamiento del Señor don Diego Fernández. de Córdoba, deán y canónigo de la Santa Iglesia de esta ciudad y provisor de ella y su arzobispado en esta sede vacante firmado de su nombre y de Melchor Pérez, notario, su fecha en quince días del mes de abril de este año en que estamos que originalmente entregué al dicho Andrés de Ocampo...esta carta de pago que es fecha en Sevilla a siete días del mes de mayo de mil e seiscientos e nueve años y el dicho otorgante lo firmó de su nombre en este registro y presentó por testigos de su conocimiento que juraron en forma de derecho que lo conocen y es el propio aquí contenido y llamarse como se ha nombrado a Juan de Solorçano, clérigo vecino de Sevilla a Santa Catalina, y a Giusepe Tazón, hermano del otorgante, que así se dijeron llamar siendo testigos Cristóbal Francisco de la Cueva y Sebastián de Ávila, escribanos de Sevilla.

\section{NICOLÁS TAZÓN. 7-V-1609. LIBROS DE CORO PARA LA IGLESIA DE SAN PEDRO DE ARCOS.}

A.P.N.S. Oficio 4 de Pedro del Carpio, libro $2^{\circ}$ de 1609.

A.H.P.S. Protocolo 2448, folios 345 recto y vuelto.

$73510 \times 355 \mathrm{~mm}$. 
Sepan cuantos esta carta vieren como yo Nicolás Tazón, escritor de libros, vecino desta ciudad de Sevilla en la collación de San Vicente otorgo e conozco que recibo de Andrés de Ocampo, escultor, vecino desta ciudad questá presente en nombre de Miguel Farfán, presbítero mayordomo de la fábrica de la iglesia del Señor san Pedro de la ciudad de Arcos, cien reales que son para en cuenta de los maravedises que montare la obra de los libros de canto que estoy haciendo para la dicha iglesia del Señor San Pedro los cuales dichos cien reales recibo realmente y con efecto en reales de plata en presencia del escribano público y testigos yuso escritos de que yo el presente escribano Pedro del Carpio doy fe y son en poder de mi el dicho Nicolás Tazón los dichos cien reales y más declaro que he recibido por cuenta de la dicha obra otros cincuenta reales del dicho mayordomo Miguel Farfán de que la dicha carta de pago firmada de mi nombre la cual y ésta se entienden ser una misma cosa y son en mi poder todos los dichos ciento y cincuenta reales de los cuales me doy por contento y pagado a mi voluntad y en razón del recibo de los dichos cincuenta reales que de presente no parece renuncio de la prueba y paga como en ella se contiene y los dichos ciento cincuenta reales se me pagan en virtud de un mandamiento del Señor don Diego Fernández de Córdoba, deán y canónigo de la Santa Iglesia de esta dicha ciudad y provisor de ella y su arzobispado en esta sede vacante firmada de su nombre y de Melchor Pérez, notario, su fecha en quince días del mes de abril de este año que originalmente entregué al dicho Andrés de Ocampo. Fecha la carta a siete días del mes de mayo de mil e seiscientos e nueve años y el dicho otorgante lo firmó de su nombre y presentó por testigos de su conocimiento que juraron en forma de derecho que lo conocen y es el propio aquí contenido y llamarse como se ha nombrado a Juan de Solorçano, clérigo vecino de Sevilla a Santa Catalina, y a Giusepe Tazón, hermano del otorgante, que así se dijeron llamar siendo testigos Cristóbal Francisco de la Cueva y Sebastián de Ávila, escribanos de Sevilla. 